\title{
Shikonin and 4-hydroxytamoxifen synergistically inhibit the proliferation of breast cancer cells through activating apoptosis signaling pathway in vitro and in vivo
}

Hong-Yan Lin ${ }^{1,2 \dagger}$, Hong-Wei Han ${ }^{1,2 \dagger}{ }^{\text {, Yin-Song Wang }}{ }^{1}$, De-Liu He ${ }^{1}$, Wen-Xue Sun ${ }^{1}$, Lu Feng ${ }^{1}$, Zhong-Ling Wen ${ }^{1}$, Min-Kai Yang ${ }^{1}$, Gui-Hua Lu ${ }^{1,3^{*}}$, Xiao-Ming Wang ${ }^{1,2^{*}}$, Jin-Liang Qi ${ }^{1,2^{*}}$ and Yong-Hua Yang ${ }^{1,2^{*}}$

\begin{abstract}
Background: Tamoxifen (TAM) is a cell type-specific anti-estrogen and is applied to improve the survival of patients with estrogen receptor positive (ER +) breast cancer. However, long-term TAM use can induce serious drug resistance, leading to breast cancer recurrence and death in patients. Further, it is almost useless among patients with estrogen receptor negative (ER -) breast cancer. Shikonin (SK) is a natural product broadly explored in cancer therapy. Some studies have demonstrated the combined treatment of SK and clinical anticancer drugs including TAM on various tumors. However, the combined effect of SK and 4-hydroxytamoxifen (4-OHT) on ER- breast cancer is not known. The current study aimed to assess the combination effects of SK and 4-OHT on human breast cancer cells, MCF-7 (ER+) and MDA-MB-435S (ER -), in vitro and in vivo and to investigate the underlying mechanisms.

Methods: CCK-8 assays and flow cytometry were conducted to determine the cell viability and apoptotic profiles of human breast cancer cell lines (MCF-7 and MDA-MB-435S) treated with SK, 4-OHT, and the combination. ROS and JC-1 assays were used to determine ROS level and mitochondrial membrane potential. Western blot analysis was performed to investigate proteins that are associated with apoptosis. Haematoxylin \& Eosin (HE) staining was used to detect the tumor and kidney morphology of mice. TUNEL and immunohistochemical staining were performed to detect Ki67 expression level and cell apoptotic profile in tumor tissues.

Results: SK and 4-OHT synergistically inhibited MCF-7 and MDA-MB-435S cell proliferation and promoted apoptosis by reducing mitochondrial membrane potential and increasing the intracellular ROS level. The combination of SK and 4-OHT activated the mitochondrial-dependent apoptosis and the death receptor pathways, significantly regulating the PI3K/AKT/Caspase 9 signaling pathway. Compared with SK and 4-OHT alone, the combination of SK and 4-OHT could better inhibit tumor growth in mice.
\end{abstract}

Conclusion: The combination of SK and 4-OHT shows highly efficient anticancer effects on breast cancer therapy. SK may be a promising candidate as an adjuvant to 4-OHT for breast cancer treatments, especially for ER- breast cancer.

Keywords: Breast cancer, Shikonin, 4-Hydroxytamoxifen, Drug combination, Apoptosis

\footnotetext{
*Correspondence: ghlu@hytc.edu.cn; guihua.lu@nju.edu.cn; wangxm07@nju. edu.cn; qijl@nju.edu.cn; yangyh@nju.edu.cn

${ }^{\dagger}$ Hong-Yan Lin and Hong-Wei Han contributed equally to this work

${ }^{1}$ State Key Laboratory of Pharmaceutical Biotechnology, Institute

of Plant Molecular Biology, School of Life Sciences, Nanjing University,

Nanjing 210023, People's Republic of China

Full list of author information is available at the end of the article
}

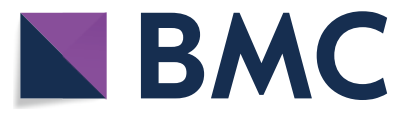

(c) The Author(s) 2020. This article is licensed under a Creative Commons Attribution 4.0 International License, which permits use, sharing, adaptation, distribution and reproduction in any medium or format, as long as you give appropriate credit to the original author(s) and the source, provide a link to the Creative Commons licence, and indicate if changes were made. The images or other third party material in this article are included in the article's Creative Commons licence, unless indicated otherwise in a credit line to the material. If material is not included in the article's Creative Commons licence and your intended use is not permitted by statutory regulation or exceeds the permitted use, you will need to obtain permission directly from the copyright holder. To view a copy of this licence, visit http://creativeco mmons.org/licenses/by/4.0/. The Creative Commons Public Domain Dedication waiver (http://creativecommons.org/publicdomain/ zero/1.0/) applies to the data made available in this article, unless otherwise stated in a credit line to the data. 


\section{Background}

Breast cancer is the most commonly diagnosed cancer and the leading cause of cancer death among females worldwide [1]. Breast cancer is treated using various therapies, including surgery [2], radiotherapy [3], endocrine therapy for patients with estrogen receptor positive $(E R+)$ breast cancer [4], and targeted therapy, such as monoclonal antibody trastuzumab targeting HER-2 [5], and chemotherapy which is an important strategy for patients diagnosed with advanced stage cancer [6]. Tamoxifen (TAM), which functions as a cell type-specific anti-estrogen, is the dominant endocrine treatment of breast cancer with demonstrated efficacy for over four decades. TAM is applied to improve the survival of patients with ER + breast cancer [7]. However, long-term TAM use can induce drug resistance, leading to breast cancer recurrence and death [8]. TAM is almost useless among patients with estrogen receptor negative $(E R-)$ breast cancer, thereby limiting its application to breast cancer treatment [9].

Combined therapy is considered as an excellent treatment strategy. Many studies aimed to restore TAM response in ER + breast cancer [10-14] and increase TAM's sensitivity in patients with ER - breast cancer through combined therapy [15-17]. The limitation of TAM can be addressed by searching for effective chemosensitizers that augment TAM's efficiency and overcome multidrug resistance.

Shikonin (SK) is a natural naphthoquinone compound extracted from the roots of the Chinese herbal plant Lithospermum erythrorhizon, exhibiting powerful anticancer activities on various breast cancer cells [18]. This effect is accomplished through multiple pathways that disrupt ER recruitment [19], induce programmed cell death [20, 21], and inhibit metalloprotease (MMP)-9 [22] and topoisomerase [23]. SK can also target tumor-specific pyruvate kinase-M2 (PKM2) and induce necroptosis [24], thereby enabling SK to avoid drug resistance. SK showed similar toxicity toward drug-sensitive and drug-resistant breast cancer cells [25]. The combined treatment of SK and clinical anticancer drugs has been widely investigated. For instance, SK can effectively sensitize A549 cells to TRIAL-induced cytotoxicity through the modulation of the JNK, STAT3 and AKT pathways [26]. In turn, TRIAL can also enhance SK induced apoptosis through reactive oxygen species (ROS)/JNK signaling in cholangiocarcinoma cells [27]. SK can be used as a synergistic agent to cisplatin to achieve excellent anticancer activity by inducing intracellular oxidative stress in colon cancer cells [28]. The combination of SK and taxol can also reverse multidrug resistance in human ovarian cancer A2780 cells in a P-glycoprotein-independent manner through enhanced ROS generation [29]. For human breast cancer cells, SK can sensitize MDA-MB-231 cell to chemotherapy by taxol through the activation of the ERKs and AKT pathways, improve mice survival and inhibit tumor growth in mice $[30,31]$. A previous work showed that SK could reduce TAM-resistance in MCF-7R cells by targeting IncRNA uc.57 and its downstream gene BCL11A [32]. Although the combination of SK and TAM was not an unprecedented strategy for ER + breast cancer therapy, their combined effects on ER- breast cancer were notknown. SK and its derivatives belong to a class of necroptotic or apoptotic inducers. They can bypass anticancer drug resistance [24, 25]. Therefore, the adjuvant activity of SK to 4-hydroxytamoxifen (4-OHT) on the inhibition of ER + and ERT - human breast cancer cell proliferation in vitro and in vivo was investigated in this work, and the mechanisms of the combination action in terms of cell apoptosis were explored.

\section{Materials and methods}

\section{Cell lines and culture conditions}

The human breast cancer cell lines (MCF-7 and MDAMB-435S) were originally obtained from the American Type Culture Collection (Manassas, VA, USA). Cells were cultured in DMEM (Gibco, USA) containing 10\% fetal bovine serum (Gibco, USA) supplemented with $1 \%$ penicillin-streptomycin (Gibco, USA) and maintained at $37{ }^{\circ} \mathrm{C}$ in a humidified atmosphere of $95 \%$ air and $5 \% \mathrm{CO}_{2}$ incubator.

\section{Reagents and antibodies}

Cell Counting Kit-8 (CCK-8, \#40203ES92) and 4-hydroxytamoxifen (4-OHT, HY16950) were purchased from MedChemExpress (MCE, USA). Shikonin (SK) was prepared by our laboratory and its structure characteristic data were shown in SI Appendix. SK and 4-OHT were dissolved in dimethyl sulfoxide (DMSO, D2650, Sigma, USA). The maximum final concentration of $0.1 \%$ DMSO was used as a control. The antibodies were purchased from proteintech group (USA).

\section{In vitro cytotoxic assay}

The in vitro cytotoxic effect of SK and 4-OHT was determined by using CCK- 8 assay kit. Cells were seeded at the density of $5 \times 10^{3}$ per well into 96 -well plated and maintained at $37^{\circ} \mathrm{C}, 5 \% \mathrm{CO}_{2}$ atmosphere overnight. Cells were treated with either SK, or 4-OHT, or the combination, and continue to be incubated for $24 \mathrm{~h}$. Then, the supernatant was discarded and fresh medium $(100 \mu \mathrm{L})$ was added into the 96 -well plated. Meanwhile, CCK-8 solution (10 $\mu \mathrm{L})$ was added to each well, after which the cells were further incubated for $2 \mathrm{~h}$. The absorbance was measured and recorded on an ELISA reader (ELx800, BioTek, USA) at a test wavelength of $450 \mathrm{~nm}$. In all experiments, three 
replicate wells were set for each drug concentration and all tests were performed at least three times.

To evaluate the synergistic efficacies of SK and 4-OHT, the $\mathrm{Q}$ value method of was used to evaluate the interaction between SK and 4-OHT on MCF-7 cells according to the equation $\mathrm{Q}=\mathrm{E}_{\mathrm{a}+\mathrm{b}} /\left(\mathrm{E}_{\mathrm{a}}+\mathrm{E}_{\mathrm{b}}-\mathrm{E}_{\mathrm{a}} \times \mathrm{E}_{\mathrm{b}}\right)$, where $\mathrm{E}_{\mathrm{a}+\mathrm{b}}$ is the synergism inhibition rate, $E_{a}$ and $E_{b}$ is the inhibition rate of drug $\mathrm{A}$ and drug $\mathrm{B}$ used alone, respectively. Synergism of the two drugs defined as a significantly greater effect when used in combination than the sum of the effects of the two drugs used alone. $\mathrm{Q}<0.85$ suggests antagonism between the two drugs, $0.85 \leq \mathrm{Q}<1.15$ addition of their effect, and $\mathrm{Q} \geq 1.15$ synergism between them.

\section{Cell apoptosis assay}

Cell apoptosis were examined using Annexin V-FITC/ PI dual staining detection kits (\#40203ES60) which were purchased from YEASEN (Shanghai, China). Briefly, MCF-7 and MDA-MB-435S cells were stained with Annexin V-FITC and PI and then monitored for apoptosis by flow cytometry. Specifically, cells were seeded at the density of $5 \times 10^{4}$ per well into 6 -well plated and maintained at $37{ }^{\circ} \mathrm{C}, 5 \% \mathrm{CO}_{2}$ atmosphere overnight. Then, cells were treated with SK, 4-OHT, or the combination for $24 \mathrm{~h}$, after which the cells were collected and washed twice with pre-cooling phosphate-buffered saline (PBS) and stained with $5 \mu \mathrm{L}$ of Annexin V and $10 \mu \mathrm{L}$ of PI $(5 \mu \mathrm{g} /$ $\mathrm{mL})$ in $100 \mu \mathrm{L}$ of $1 \times$ binding buffer $(10 \mathrm{mM}$ HEPES, $\mathrm{pH}$ 7.4, $140 \mathrm{mM} \mathrm{NaOH}, 2.5 \mathrm{mM} \mathrm{CaCl}$ ) for $15 \mathrm{~min}$ at room temperature in the dark. Apoptotic cells were quantified using BD FACScalibur Flow Cytometer (BD, USA). Data were analyzed using Flowjo 7.6.1 software. Both early apoptotic (Annexin V + and PI-) and late apoptotic (Annexin $\mathrm{V}+$ and $\mathrm{PI}+$ ) cells were detected.

\section{Mitochondrial membrane potential $(\Delta \psi \mathrm{m})$ analysis}

Mitochondrial transmembrane potentials were detected by using a Mitochondrial Membrane Potential Assay Kit (\#C2006, Beyotime Institute of Biotechnology, Haimen, China) with JC-1 dye (lipophilic cation 5, 5', 6, 6'-tetrachloro-1, 1', 3, 3'-tetraethylbenzimidazolcarbocyanine iodide). Briefly, cells were seeded into 6 -well plates at $5 \times 10^{4}$ cells per well and maintained at $37^{\circ} \mathrm{C}, 5 \% \mathrm{CO}_{2}$ atmosphere overnight. After treated with SK, 4-OHT, or the combination for $24 \mathrm{~h}$, the cells were collected and washed twice with ice-cold PBS. Then cells were re-suspension with $1 \times \mathrm{JC}-1$ staining buffer and incubated in $\mathrm{CO}_{2}$ incubator for 15-30 min. Finally, cells were washed twice with PBS and re-suspension with $500 \mu \mathrm{L}$ PBS before being analyzed by BD FACScalibur Flow Cytometer (BD, USA).
Intracellular reactive oxygen species (ROS) levels detection by flow cytometry

Intracellular reactive oxygen species (ROS) levels were measured by ROS Assay Kit (\#S0033, Beyotime Institute of Biotechnology, Haimen, China) with an oxidation-sensitive fluorescent probe dye, DCFH-DA (2, 7- dichlorodihydro fluorescein diacetate). In brief, cells were seeded in 6 -well plates $\left(5 \times 10^{3}\right.$ cells per well $)$ and incubated at $37^{\circ} \mathrm{C}, 5 \% \mathrm{CO}_{2}$ atmosphere for $24 \mathrm{~h}$. Exponentially growing cells were then incubated with $3 \mu \mathrm{M}$ SK, $17.5 \mu \mathrm{M}$ 4-OHT, or the combination for $12 \mathrm{~h}$, after which the cells were collected and washed with PBS, and then incubated at $37{ }^{\circ} \mathrm{C}$ with DMEM containing $10 \mu \mathrm{M}$ DCFHDA for $30 \mathrm{~min}$. After that, cells were washed three times using serum-free DMEM. The samples were finally analyzed using a FACScan flow cytometer and Flowjo 7.6.1 software.

\section{Protein extraction and western boltting}

Total proteins were extracted from human breast cancer cells after treated with RIPA lysis buffer containing 1\% PMSF and centrifuged at $16,000 \mathrm{~g}$ at $4{ }^{\circ} \mathrm{C}$ for $15 \mathrm{~min}$ using Eppendorf 5810R centrifuge. Protein concentrations were measured using the BCA Protein Assay kit (\#23227 Thermo Fisher Scientific, USA). Approximately $80 \mu \mathrm{g}$ of total protein were separated by $10 \%$ SEMS-polyacrylamide gels and transferred to PVDF membranes. After blocked with $5 \%$ defatted milk solution, membranes were incubated with primary antibodies, such as Smac/Diablo (\#10434-1-AP, rabbit polyclonal IgG, 1: 1000 dilution); PI3K (\#13329-1-AP, rabbit polyclonal IgG, 1: 1000 dilution), AKT (\#10176-2-AP, rabbit polyclonal IgG, 1: 1000 dilution), Caspase 9 (\#10380-1-AP, rabbit polyclonal IgG, 1: 1000 dilution), PARP-1 (\#66520-1-Ig, mouse monoclonal IgG, 1: 600 dilution), Bad (\#10435-1-AP, rabbit polyclonal IgG, 1: 1000 dilution), Bcl-2 (\#12789-1-AP, rabbit polyclonal IgG, 1:1000 dilution), Bax (\#50599-2-Ig, rabbit polyclonal IgG, 1:1000 dilution), Caspase 8 (\#13423-1-AP, rabbit polyclonal IgG, 1: 1000 dilution), Fas (\#13098-1AP, rabbit polyclonal IgG, 1:1000 dilution), Bid (\#109881-AP, rabbit polyclonal IgG, 1: 1000 dilution), Caspase-3 (\#19677-1-AP, rabbit polyclonal IgG, 1:1000 dilution) and GAPDH (\#10494-1-AP, rabbit polyclonal IgG, 1: 1000 dilution) at $4{ }^{\circ} \mathrm{C}$ overnight. After thrice washing in TBST for each $5 \mathrm{~min}$, membranes were incubated with HRP-conjugated secondary antibodies (\#SA00001-1, \#SA00001-2, 1: 5000 dilution) at room temperature for $2 \mathrm{~h}$. Detection was performed by an enhanced chemiluminescent reagent (Thermo Fisher Scientific, USA) according to the manufacturer's instructions. Bands were then recorded by a digital camera (Tanon 5200, Shanghai, China). Finally, the results were analyzed with Image 
J Software (National Institutes of Health, BetheSEMa, Maryland, USA), and all the targeted proteins were normalized to GAPDH.

\section{Animals and treatment}

Female nude mice at 6-8 weeks old were purchased from Model Animal Research Center of Nanjing University (Nanjing, China). They were kept at $22{ }^{\circ} \mathrm{C}-24{ }^{\circ} \mathrm{C}$ with a $12 \mathrm{~h}$ light $/ 12 \mathrm{~h}$ dark cycle in a pathogen-free isolation facility. They were allowed to adapt for 1 week prior to experimentation. Cultured MCF-7 cells were washed and re-suspended in ice-cold PBS. Portions of the suspension $\left(6 \times 10^{6}\right.$ cells in $\left.0.1 \mathrm{~mL}\right)$ were subcutaneously injected into the right flanks of each mouse. After 2 weeks, the mice bearing tumors $\left(100 \mathrm{~mm}^{3}\right.$ on average) were randomly grouped into four $(n=8$ mice per group) in accordance with tumor volumes. SK $(1.5 \mathrm{mg}$ / $\mathrm{kg})$ and 4-OHT $(3 \mathrm{mg} / \mathrm{kg})$ were dissolved in DMSO and administered once every 2 days for six times via intraperitoneal injection. The vehicle (DMSO)-treated group was included as a control. The body weight and tumor volumes were measured and recorded every 2 days. The long $(L)$ and short $(S)$ diameters of a tumor were measured with a Vernier caliper, and the tumor volume was calculated using the following formula: $L \times(S)^{2} / 2$. On the 15 th day, all the mice were euthanized. The tumors were separated, and their weights were determined. The tumor growth inhibition rate was calculated using the following formula: $\left(1-W_{1} / W_{2}\right) * 100 \%$, where $W_{1}$ is the tumor wet weight of drug group, and $W_{2}$ is the tumor wet weight of the control group. All animal experiments were conducted in strict compliance with the Guidelines for the Care and Use of Laboratory Animals of Nanjing University and approved by the Laboratory Animal Ethics Committee of School of Life Sciences, Nanjing University.

\section{Haematoxylin \& Eosin (HE) staining}

The tumor and kidney tissues obtained from mice were fixed in $4 \%$ papaformaldehyde for over $12 \mathrm{~h}$ and were embedded in paraffin. Then, optimum cutting temperature packages tissues to slice as $20-30 \mu \mathrm{m}$ sections. Then, sections were stained with haematoxylin and eosin.

\section{Immunohistochemical analysis}

Immunohistochemistry was performed for Anti-Ki67. The tissues were incubated with primary antibody (ab15580, Abcam, USA) at $4{ }^{\circ} \mathrm{C}$ overnight after deparaffinized and rehydrated. The Alexa Fluor 488 labeled antirabbit secondary antibody (ab150077, Abcam, USA) were treated $1 \mathrm{~h}$ at room temperature. Finally, signals were developed with Hematoxylin and DAB (Dako, Agilent Technologies, USA).

\section{TUNEL staining analysis}

Cell apoptosis of tumor tissues were performed by using TUNEL Apoptosis Assay Kit (TUN11684817, Roche, Swiss) according to the instructions.

\section{Data and statistical analysis}

All experiments were repeated at least three times. Data are presented as mean \pm S.E.M. and statistical comparisons among groups of controls, individual agents, and combinations of agents using one-way ANOVA using GraphPad PRISM5 (Graphpad Inc., La Jolla, USA). ${ }^{*} P<0.05$ was considered as statistically significant; ** $P<0.01$ was considered as statistically very significant.

\section{Results}

Combination of SK and 4-OHT exhibited synergistic or enhanced anticancer effects on MCF-7 and MDA-MB-435S

CCK- 8 assay was used to evaluate the antiproliferation effects of SK, 4-OHT, and their combination on the two types of breast cancer cell lines, MCF-7 (ER+) and MDA-MB-435S (ER-). The combination effects of SK and 4-OHT were evaluated by calculating the $\mathrm{Q}$ values. The results shown in Fig. 1 indicates that the effects of all combination groups on MCF-7 cell line were synergistic $(\mathrm{Q}>1.15)$, whereas only two-thirds of the combination groups showed synergistic effects on MDA-MB-435S cell line. The other three combinations showed enhanced anticancer effects $(1.15>\mathrm{Q}>0.85)$. By comparing the $Q$ values shown in Additional file 1: Table S1, we found that the combination of $3 \mu \mathrm{M}$ SK and $15 \mu \mathrm{M}$ 4-OHT showed the strongest synergistic effect on MCF-7 cell line $(\mathrm{Q}=1.93)$. The combination significantly inhibited the cell viability with an inhibition rate of $47 \%$. The inhibition rates of single drug SK $(3 \mu \mathrm{M})$ and 4-OHT $(15 \mu \mathrm{M})$ were $12 \%$ and $14 \%$, respectively. For MDA-MB-435S cell line, the best synergistic combination was $3 \mu \mathrm{M}$ SK and $17.5 \mu \mathrm{M} 4-\mathrm{OHT}(\mathrm{Q}=1.34)$. The inhibition rate of such a combination reached 66\%, whereas the inhibition rates of single drug SK $(3 \mu \mathrm{M})$ and 4-OHT $(17.5 \mu \mathrm{M})$ were $41 \%$ and $14 \%$, respectively (Additional file 1 : Table S2). Therefore, such combinations were the most optimal treatments and were subsequently used in the in vitro experiments.

\section{Combination of SK and 4-OHT induced cell apoptosis in MCF-7 and MDA-MB-435S}

Annexin V/propidium iodide (PI) double staining results demonstrated that the combination of SK and 4-OHT could induce cell apoptosis more effectively than the cells that were only treated with SK or 


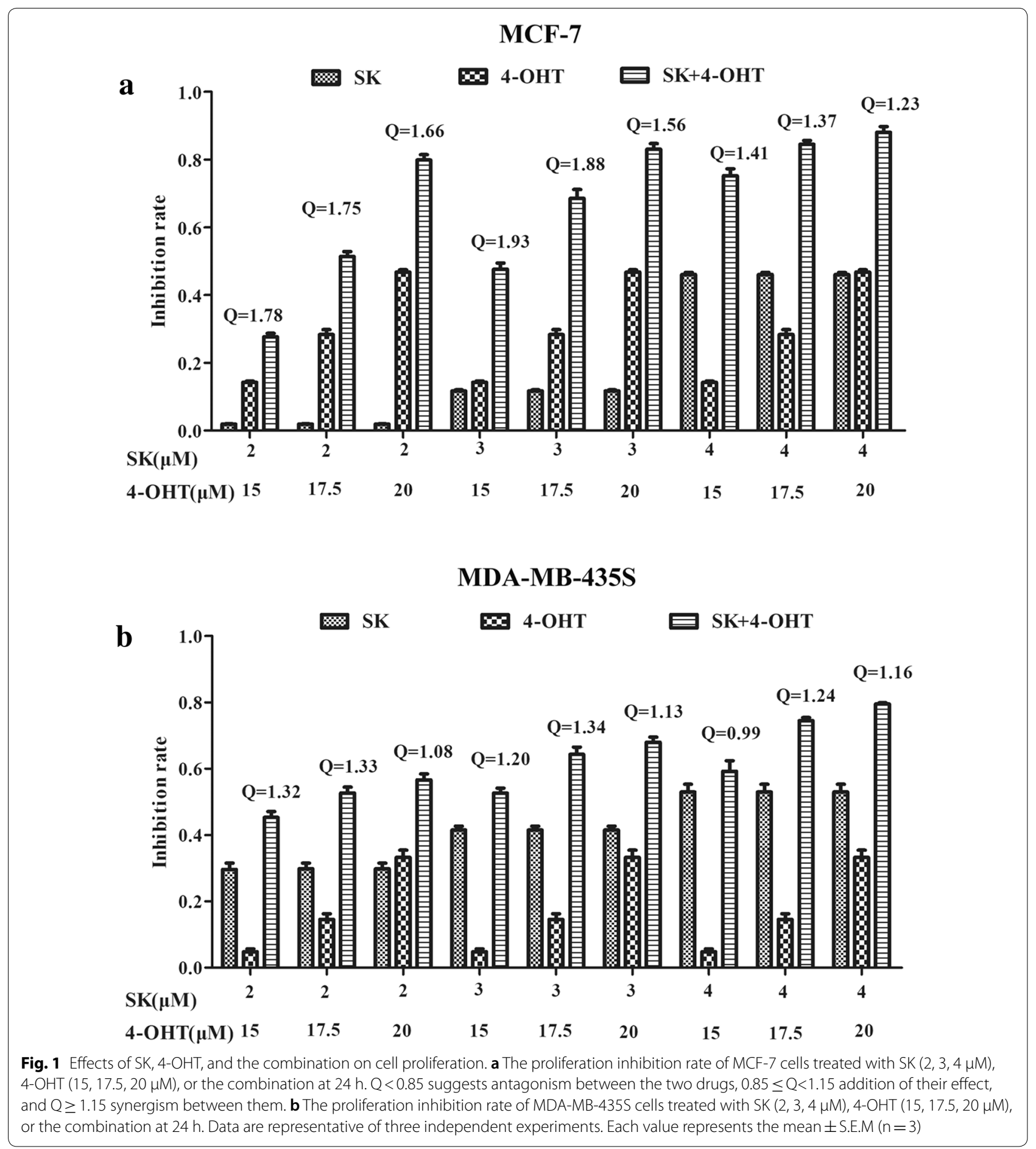

4-OHT in MCF-7 and MDA-MB-435S (Fig. 2). Further analysis indicated that the combination significantly increased early apoptotic cells in the MCF-7 cell line (Fig. 2c) and late-apoptotic cells in MDA-MB-435S cell line (Fig. 2f).
Combination of SK and 4-OHT decreased the mitochondrial membrane potential in MCF-7 and MDA-MB-435S

The mitochondrial membrane potential is an important parameter that regulates mitochondrial functionality and cellular processes. Its dissipation may initiate apoptosis [33]. As shown in Fig. 3a, SK and the combination 
(See figure on next page.)

Fig. 2 Effects of SK, 4-OHT, and the combination on cell apoptosis. a Representative dot-plots from cytometrically illustrating apoptotic status in MCF-7 cells. b Statistic analysis of apoptotic cells (percentage of cells in Q2 and Q3). c Statistic analysis of early (E, percentage of cells in Q3) and late ( $L$, percentage of cells in Q2) apoptotic cells. d Representative dot-plots from cytometrically illustrating apoptotic status in MDA-MB-435S cells. e Statistic analysis of apoptotic cells (percentage of cells in Q2 and Q3). $\mathbf{f}$ Statistic analysis of early (E, percentage of cells in Q3) and late ( $L$, percentage of cells in Q2) apoptotic cells. Images are representative of three independent experiments. Data are mean \pm S.E.M. from three independent experiments ${ }^{*} P<0.05,{ }^{* *} P<0.01$ compared with the negative control; ${ }^{\# \#} P<0.01$ compared with the combination group)

treatment could decrease the mitochondrial membrane potential in MCF-7 cells but not 4-OHT. Moreover, compared with SK (high $\Delta \Psi m 90.2 \%$ ) and 4-OHT (high $\Delta \Psi m$ 95.2\%), the combination (high $\Delta \Psi m 69.1 \%$ ) treatment caused a more serious loss of membrane potential (Fig. 3b). The PI staining results in Fig. 3c show that the above drug concentrations and treatment times could not cause false positives by inducing late apoptosis. The reliability of mitochondrial membrane potential results was ensured. Meanwhile, a similar result was observed in the MDA-MB-435S cell line. The combination treatment resulted in the lowest mitochondrial membrane potential among the treatments, as follows: combination treatment, 53.6\%; SK, 82.7\%; and 4-OHT, 86.4\% (Fig. 3d, e).

\section{Combination of SK and 4-OHT increased intracellular ROS level in MCF-7 and MDA-MB-435S}

The effects of SK and 4-OHT alone or combination on intracellular ROS level was determined by flow cytometry in MCF-7 and MDA-MB-435S cell lines. The combination group induced the generation of ROS more effectively than SK and 4-OHT in MCF-7 and MDA-MB435S cells (Fig. 4).

\section{SK and 4-OHT combination regulated the expression level of apoptotic-related proteins}

The effect of SK combined with 4-OHT on the expression of apoptosis-related proteins were studied using Western blot assay. The mitochondrial apoptosis pathway and the death receptor pathway were activated in MCF-7 and MDA-MB-435S after the combination treatment (Fig. 5). In the mitochondria-dependent apoptosis pathway, both cells showed increased expressions of Cleaved PARP and pro-apoptotic factor Smac, but the expression of the anti-apoptotic protein Bcl-2 was downregulated. The combination also increased the expression of Bax and Cleaved-caspase 3 in MDA-MB-435S (Fig. 5a, d). The key proteins in the PI3K-AKT-Caspase 9 pathway were detected, and the expressions of PI3K in MCF-7 and MDA-MB-435S cells were significantly reduced after the combination treatment (Fig. 5b, e). However, AKT expression was markedly decreased in MCF-7, but not significantly in MDA-MB-435S. The combination treatment increased the expression of Cleaved caspase 9 in the two cell lines. For the death receptor pathway, the combined group showed high Fas protein and Cleaved-caspase 8 expression but low downstream Bid protein expression compared with the SK and 4-OHT groups (Fig. 5c, f). The above results elucidated the molecular mechanism of the SK and 4-OHT synergistic effects on MCF-7 and MDA-MB-435S in terms of apoptotic pathways.

\section{Combined therapy suppressed tumor growth in vivo}

Female BALB/c mice were subcutaneously inoculated with MCF-7 cells to form sizeable tumors and to determine the in vivo safety and efficiency of the combined treatment. The mice were randomly grouped into four, and each group was treated with the vehicle (DMSO), SK $(1.5 \mathrm{mg} / \mathrm{kg})$, 4-OHT (3 mg/kg), and their combination, respectively. As shown in Fig. 6a, c, SK and 4-OHT monotherapy could effectively inhibit the growth of transplanted tumor in nude mice compared with the control group. The combination group had the smallest mean tumor volume. Furthermore, the mean tumor weight of the combination group was $0.18 \mathrm{~g}$, which was $58 \%$ lower than that of $4-\mathrm{OHT}$ and $47 \%$ lower than that of SK (Fig. 6b). In vivo, the tumor growth inhibition rate of the combination was $76.65 \%$, which was higher than those of SK (57.20\%) and 4-OHT (45.44\%) independent treatments (Additional file 1: Table S3). In addition, 4-OHT and the combination did not significantly reduce the mice body weight. By contrast, SK had certain side effects on mice and had a slight effect on their body weight (Fig. 6d). Further immunohistochemical analysis and H\&E staining results of tumor tissues indicated that the combination could inhibit tumor cell more effectively than SK or 4-OHT (Fig. 7ac). The combination treatment resulted in less severe renal injury compared with SK (Fig. 7d) and induced more significant apoptosis in tumor tissues than SK or 4-OHT monotherapies (Fig. 7e, f).

\section{Discussion}

SK is a well-known active ingredient isolated from the root of a Chinese herbal medicine that has been used for thousands of years. Its extensive and remarkable antitumor activities, including its anti-breast [18], gastric [34], colon [35], glioma [36] effects, have attracted 
$\mathbf{a}$

MCF-7
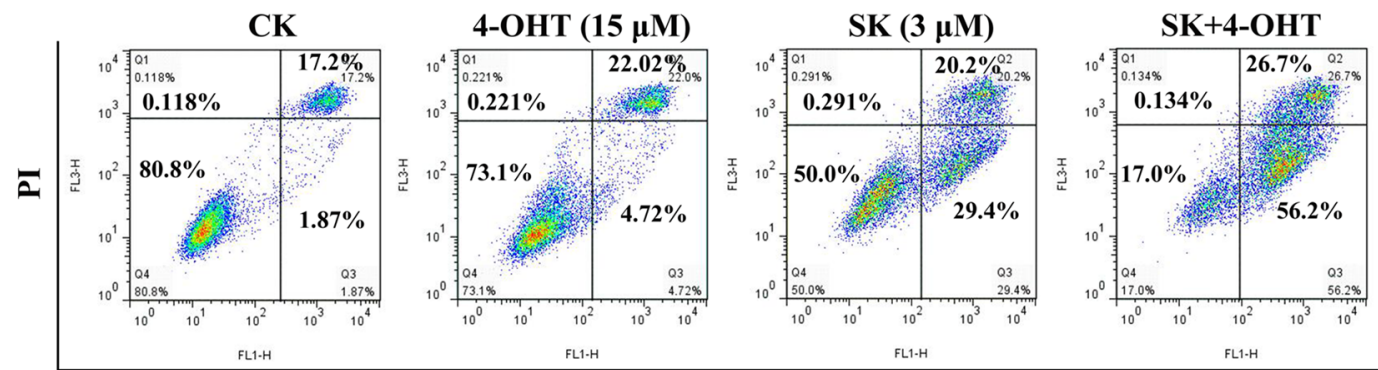

\section{Annexic-V}

b

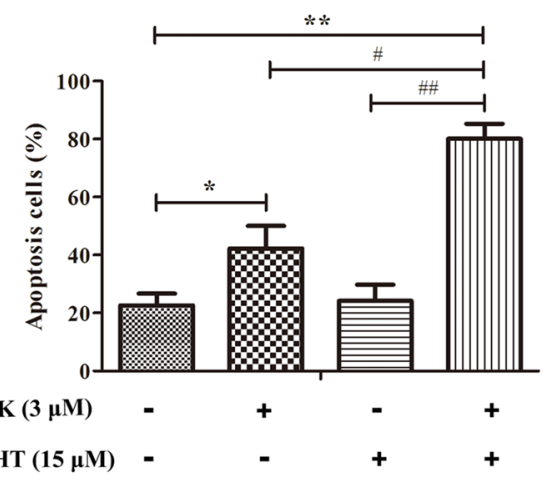

c

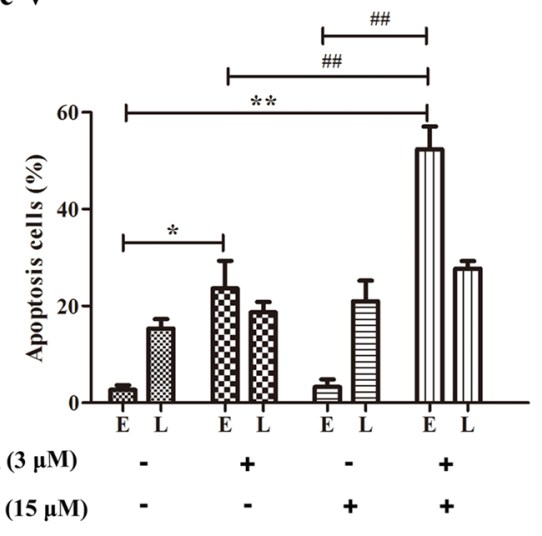

d

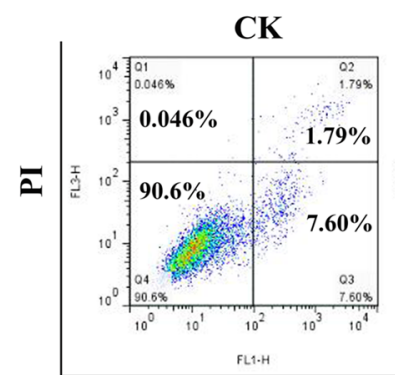

4-OHT (17.5 $\mu \mathrm{M})$

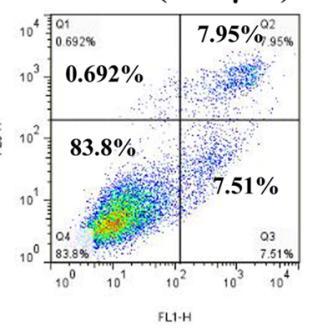

MDA-MB-435S
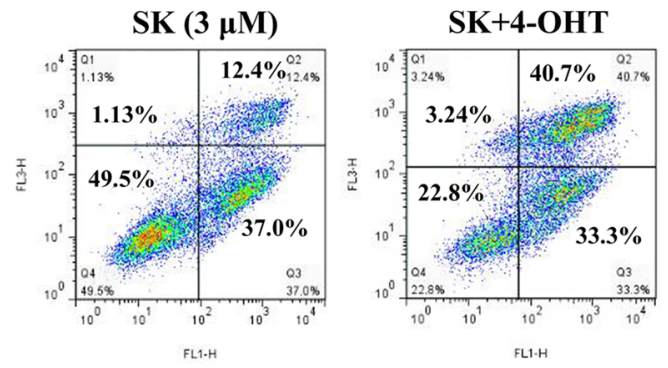

Annexic-V

e

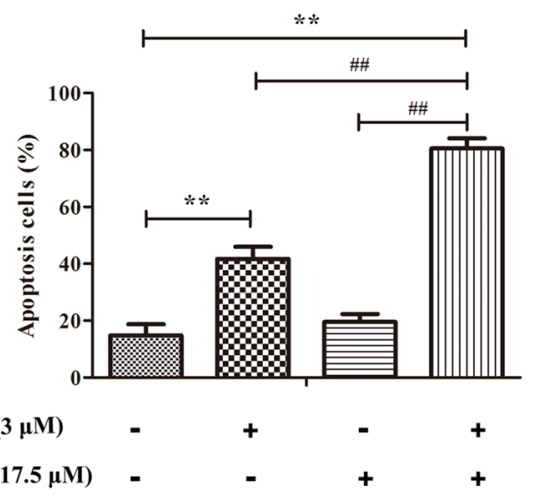

f

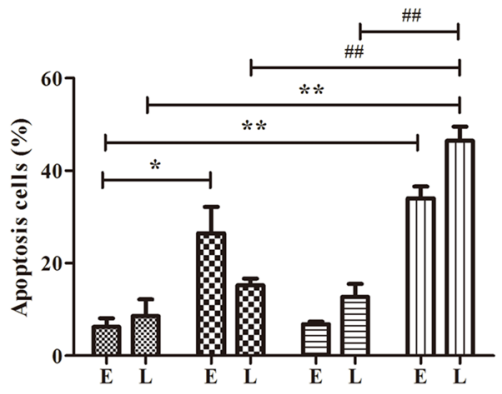

SK $(3 \mu \mathrm{M})$ 4-OHT (17.5 $\mu \mathrm{M})$ 
MCF-7

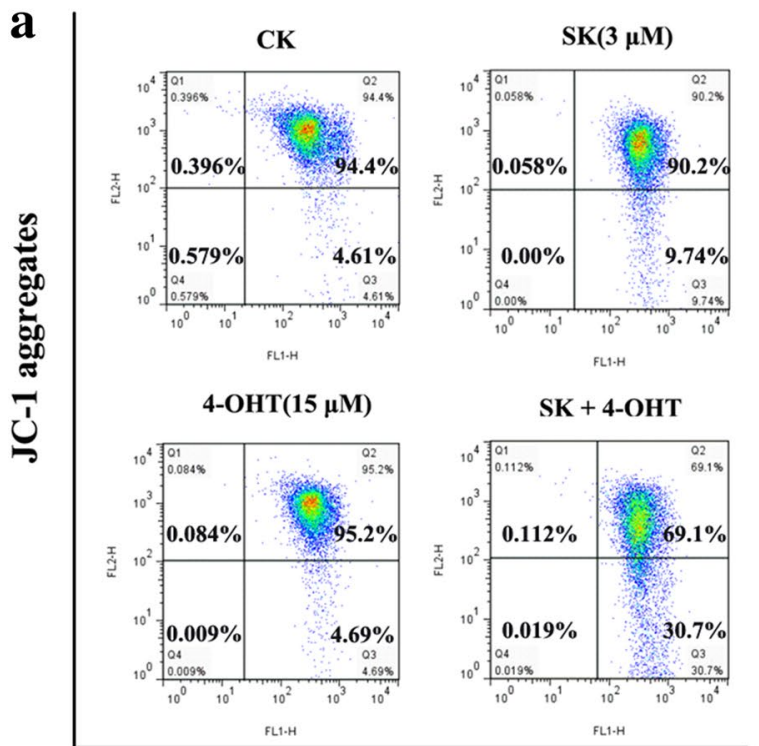

\section{JC-1 monomers}

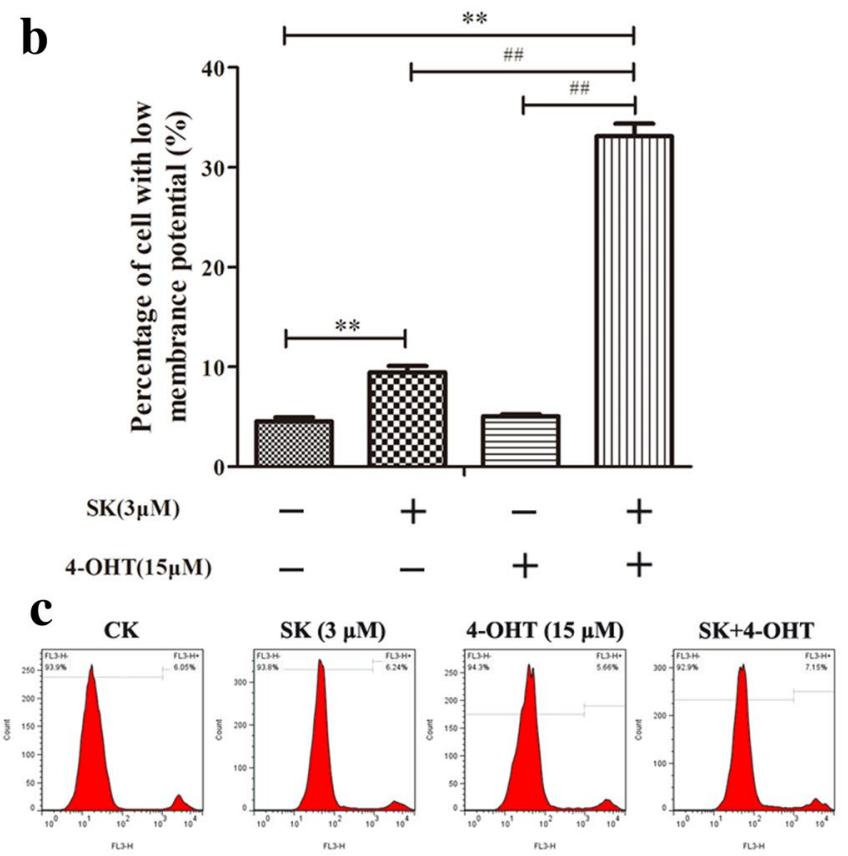

\section{MDA-MB-435S}

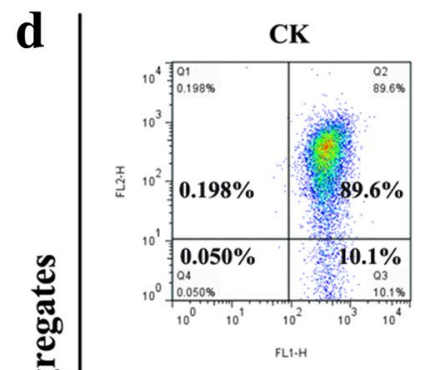

4-OHT(17.5 $\mu \mathrm{M})$

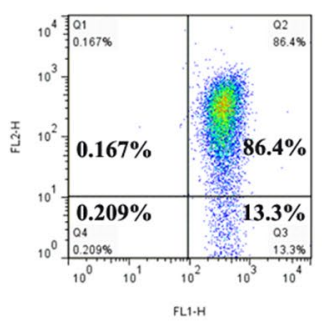

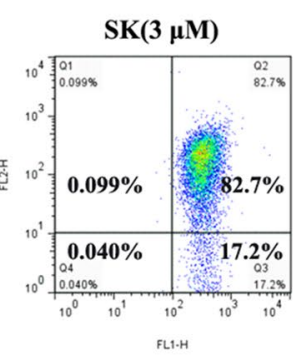

SK + 4-OHT

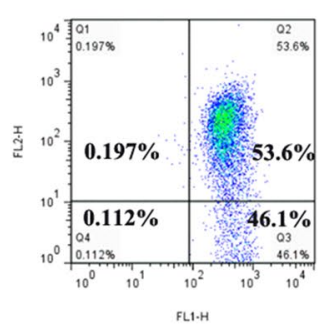

$\mathbf{e}$
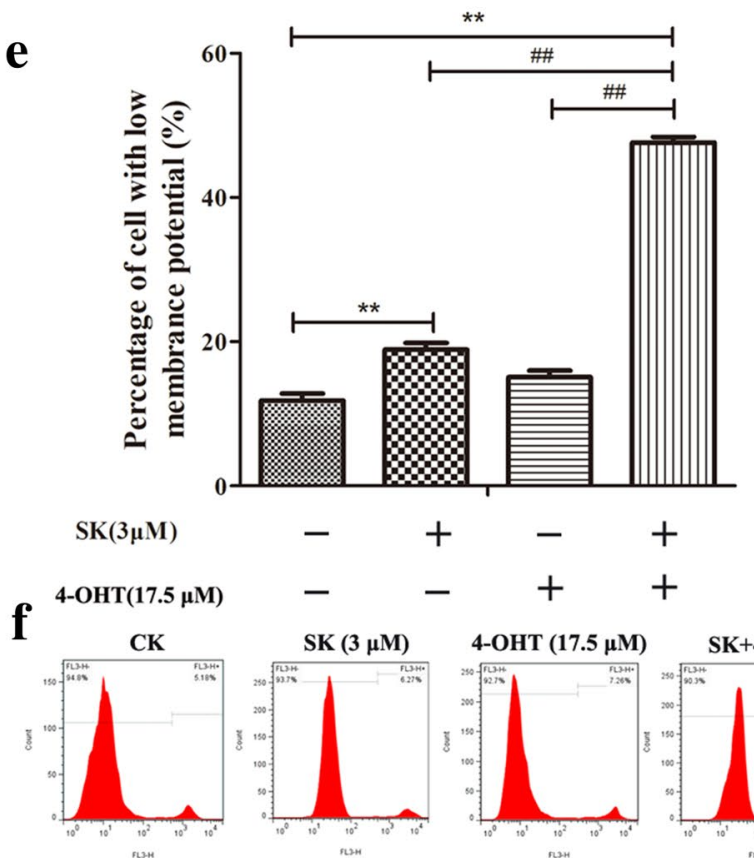

$+$

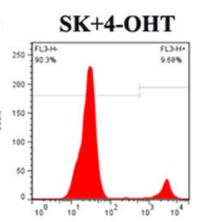

Fig. 3 Effects of SK, 4-OHT, and the combination on decreasing the mitochondrial membrane potential of cells. a Flow cytometry analysis of MCF-7 cells with high $\Delta \Psi_{m}(\%)$ by JC-1 staining. b Statistic analysis of MCF-7 cells with low $\Delta \Psi_{m}$ (\%) (percentage of cells in Q3). c The representative image of PI staining of MCF-7 cells. $\mathbf{d}$ Flow cytometry analysis of MDA-MB-435S cells with high $\Delta \Psi_{m}$ (\%) by JC-1 staining. e Statistic analysis of MDA-MB-435S cells with low $\Delta \Psi_{m}$ (\%) (percentage of cells in Q3). $\mathbf{f}$ The representative image of PI staining of MDA-MB-435S. Data are mean \pm S.E.M. from three independent experiments ( ${ }^{* *} P<0.01$ compared with the negative control; ${ }^{*} P<0.01$ compared with the combination group) 


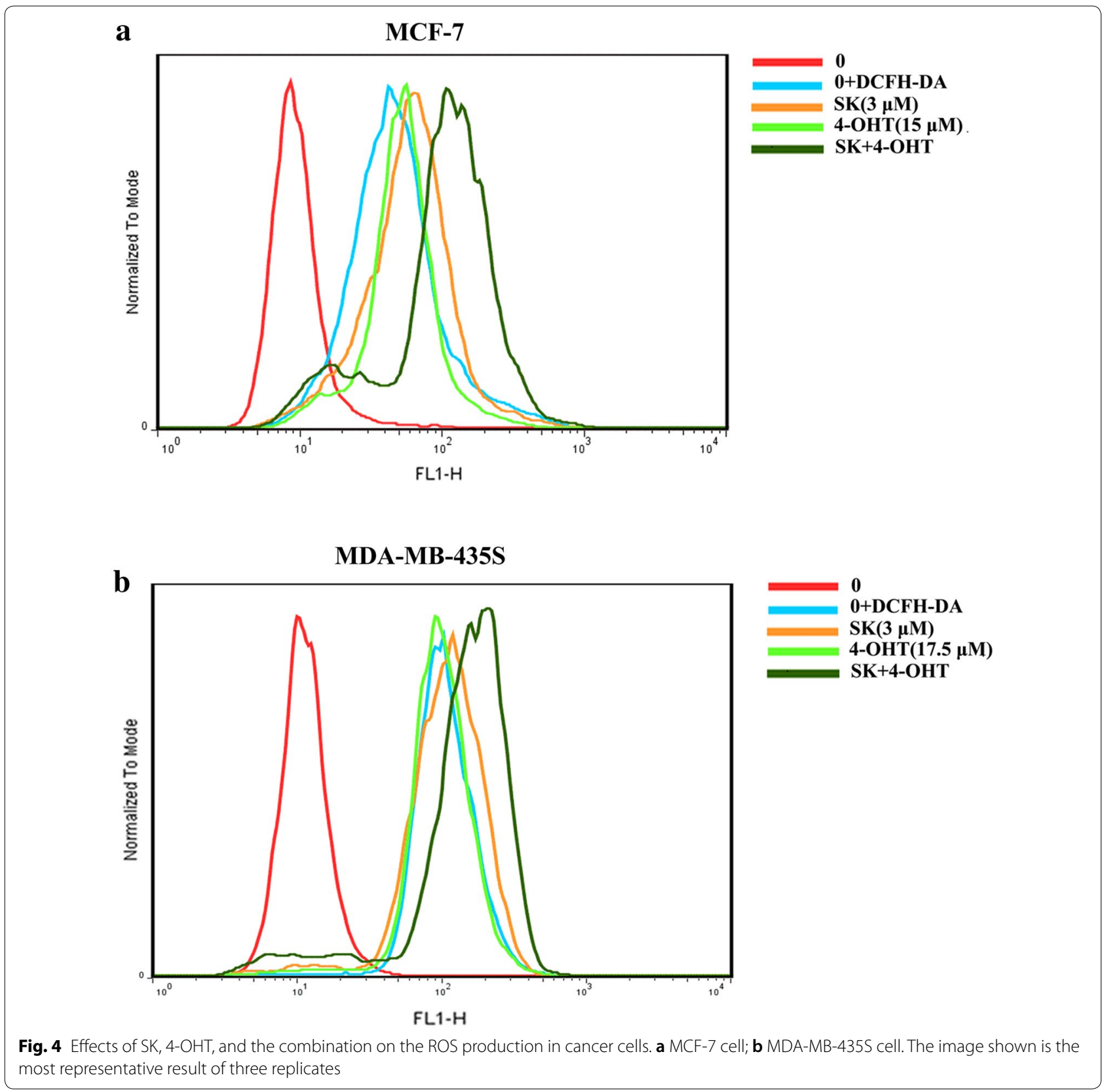

considerable attention. Breast cancer research findings show SK could inhibit estrogen-dependent tumor cell growth and promote the anti-estrogen effect of TAM, restoring its efficacy against cancer cells [19]. In addition, SK could bypass cancer drug resistance by targeting the "weak point" of apoptotic/drug resistant cancers [24, 25]. This "weak point" is necroptosis, a basic cell-death pathway distinct from apoptosis. SK can induce apoptosis and necroptosis in drug-sensitive and resistant cancer cell lines by targeting PKM2, which is universally expressed in cancer cells and controls the last-limiting step of glycolysis [37]. SK can also modulate the PI3K/AKT pathway to suppress the growth and survival of cancer cells [32]. The overexpression of PI3K/AKT is closely related to TAM resistance [38]. Thus, SK might be beneficial for the prevention of ER + breast cancer cell resistance to TAM and could be applied to ER- breast cancer. Although the combination of SK and TAM has been studied, including promotion of the anti-estrogen effect of TAM and modulation of PI3K/AKT pathway, the bypassing of cancer 


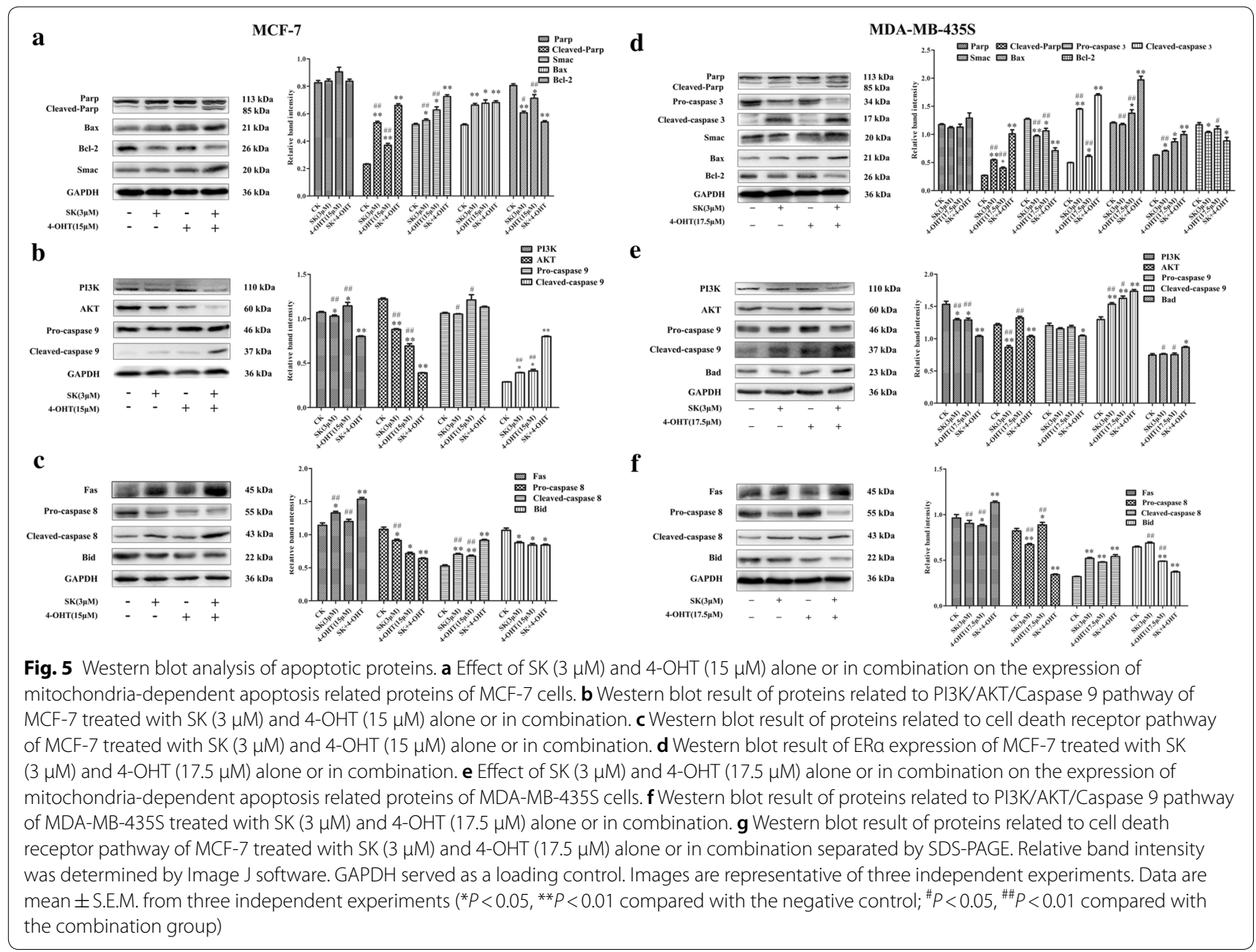

drug resistance by targeting the "weak point" of cancer has not been investigated further.

In the present study, MCF-7 (ER+) and MDA-MB435S (ER-) cells were used to explore the auxiliary effect of SK to 4-OHT (an active metabolite of TAM in vivo) focusing on cell apoptosis. The optimum concentrations of SK and 4-OHT were determined through CCK- 8 assay. The results of comparison and analysis showed that 4-OHT caused a more potent inhibition of MCF-7 than MDA-MB-435S, which was in accordance with its property as an ER + inhibitor. By contrast, SK exhibited more potent inhibition on MDA-MB-435S than MCF-7, which was also consistent with its toxicity toward drug-sensitive and resistant breast cancer cells. The synergistic effects of SK and 4-OHT on MCF-7 cell were considerably better than on MDA-MB-435S cell. This result is attribute to SK's inhibition of the growth of estrogen-dependent tumor cells and promotion of the anti-estrogen effect of 4-OHT. The following cell apoptosis results showed that SK and 4-OHT had significant synergistic effects on increasing apoptosis in MCF-7 and MDA-MB-435S cells. However, the combination treatment remarkably increased the percentage of early apoptotic cells in the MCF-7 cell and the percentage of late apoptotic cells in the MDA-MB-435S cell. This difference is consistent with their effects on the changing mitochondrial membrane potential. The synergistic effects of SK and 4-OHT on decreasing mitochondrial membrane potential in MCF-7 cell were more significant than on that in MDA-MB-435S cell. Finally, the in vivo experiment indicated that SK also exhibited synergistic effects with 4-OHT on the suppression of tumor growth. 4-OHT can reduce the toxic side effects of SK dramatically, but this result requires further investigation.

This work has some limitations. First, only two types of cell lines were used in the experiment. More types of breast cancer cell lines could be taken into account, 


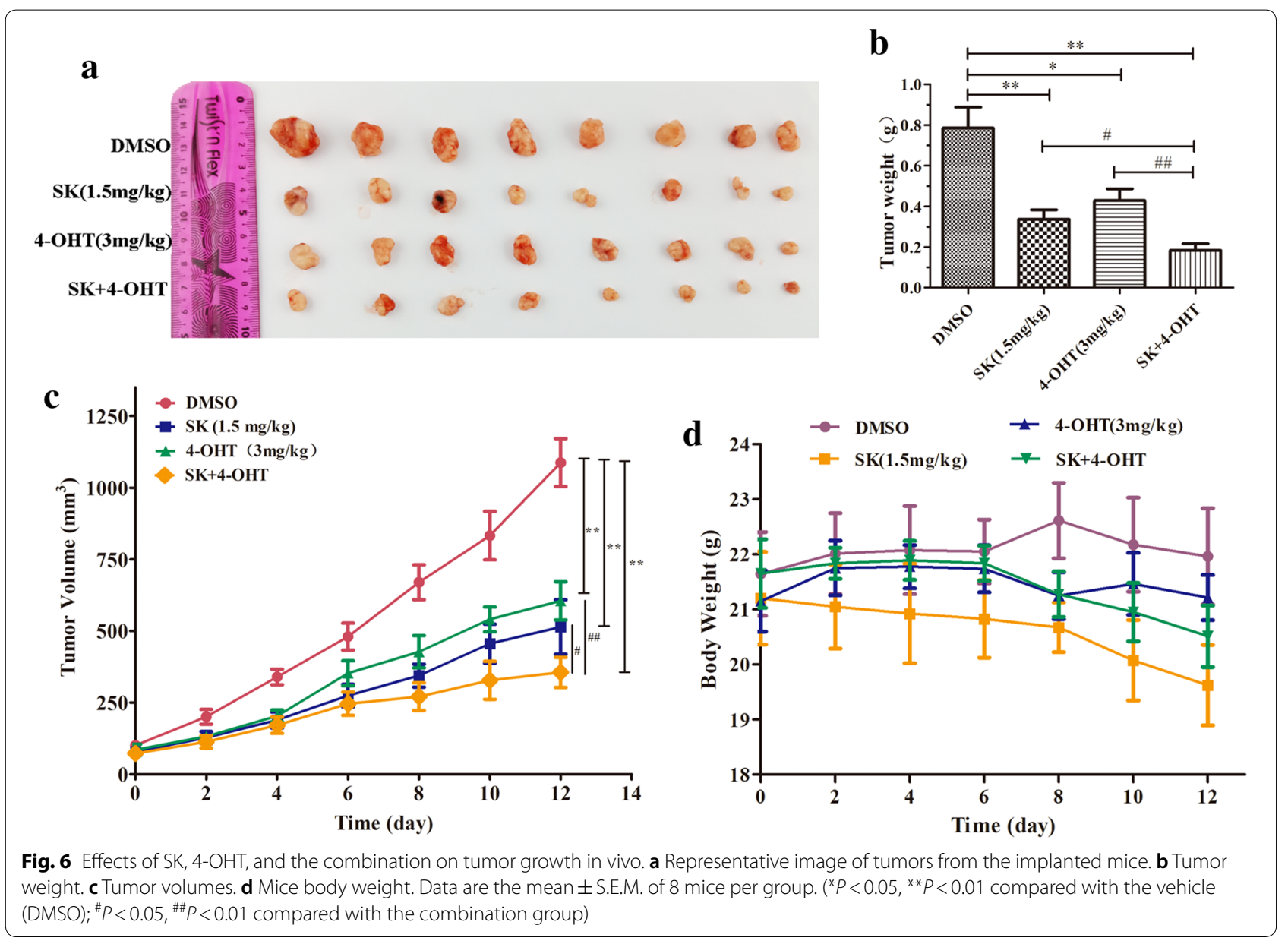

including the TAM-resistant cell line, MCF-7R. We also investigated the combined effects of SK and 4-OHT on MDA-MB-231 before (Additional file 1: Table S4 and Figure S1). However, their combined effects on MDAMB-231 cells were simple additive or even antagonistic. The combination of SK and 4-OHT may trigger different reactions on different types of cells. This combination could bypass drug resistance by inducing necroptosis and apoptosis. However, programmed cell death has been updated and expanded to 12 types in the last 20 years, and the barriers between them are not strict. Thus, other mechanisms of programmed cell death induced by the combined therapy cannot be ruled out. Third, the in vivo study lacked survival data because all mice were alive after six treatments. The combined effects of SK and 4-OHT on MDA-MB-435S xenograft model were not studied due to the low tumor formation rate of MDAMB-435S cells. As such, additional preclinical data are needed for the clinical applications of SK.
As to the efficiency of Chinese herbal medicine, there still exists a controversial debate to some extent due to its scientific nature of Chinese medicinal ways unlike western medical ways. Undoubtedly, Chinese herbal medicine might be more effective as one disease shows more complex, especially for some complicated and chronic diseases with unknown or complex pathophysiology, such as Alzheimer's disease, which caused by multiple factors, since such traditional medicine usually contains multiple compounds as a complex with known or unknown multi-functional targets [39, 40]. Another approach for modernization of Chinese herbal medicine is to identify single compound or simple complex with strong medical effect from Chinese traditionally medicinal herbs. Typically, SK is an active natural naphthoquinone compound as one example, which is derived from the dried root of traditional Chinese medicinal herb Zicao. Currently, we obtain SK as single compound through modern separation methods, and investigate its anticancer activity with possible 


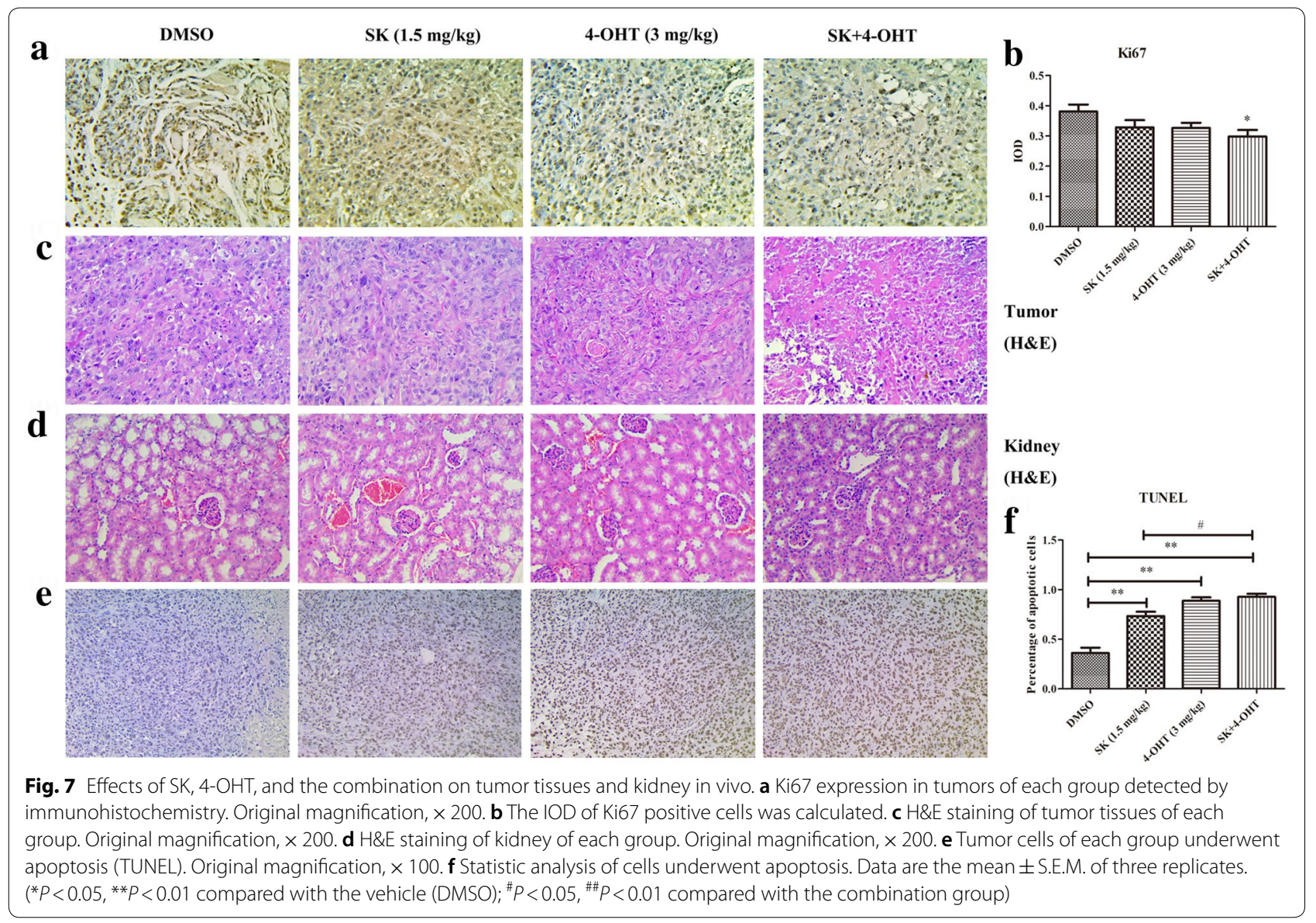

underlying mechanism, in order to promote efficiently intracellular delivery with target through modern approaches, and finally intend to develop some effective treatment for human cancer as did in other reports [41], which could be regarded as one attempt of modern experimentations of Chinese traditionally herbal medicine and should be enhanced further for the perspective of Chinese medicine.

\section{Conclusions}

This study demonstrated that combined SK and 4-OHT synergistically inhibited MCF-7 and MDA-MB-435S proliferation in vitro by increasing ROS, decreasing mitochondrial potential, and inducing cell apoptosis mainly through mitochondrial-dependent apoptosis pathway. The combined therapy works in vivo. Therefore, SK may be a potent adjuvant agent to 4-OHT by preventing TAM- resistance in ER + breast cancer treatment and expanding the use of 4-OHT in ERbreast cancer treatment.

\section{Supplementary information}

Supplementary information accompanies this paper at https://doi. org/10.1186/s13020-020-00305-1.

Additional file 1: Table S1. Inhibition of MCF-7 cell proliferation and Q value by the treatment of SK, 4-OHT, and the combination. Table S2. Inhibition of MDA-MB-435S cell proliferation and $Q$ value by the treatment of $\mathrm{SK}, 4-\mathrm{OHT}$, and the combination. Table S3. Tumor growth inhibition rate in mice. Table S4. Inhibition of MDA-MB-231 cell proliferation and Q value by the treatment of SK, 4-OHT, and the combination. Figure S1. Effects of $\mathrm{SK}, 4-\mathrm{OHT}$, and the combination on MDA-MB-231 cell proliferation. Figure S2. ${ }^{1}$ H NMR of Shikonin. Figure S3. ${ }^{13} \mathrm{C}$ NMR of Shikonin. Figure S4. HPLC of Shikonin. Figure S5. Circular dichroism spectrum of Shikonin. Figure S6. Mass spectrum of Shikonin.

\section{Abbreviations}

4-OHT: 4-Hydroxytamoxifen; ER+: Estrogen receptor positive; SK: Shikonin; ROS: Reaction oxygen species; TAM: Tamoxifen; ER: Estrogen receptor negative; MMP: Metalloprotease; PKM2: pyruvate kinase-M2; CCK-8: Cell Counting Kit-8; PI: Propidium lodide; PBS: Phosphate buffer saline.

\section{Acknowledgements}

Not applicable.

\section{Authors' contributions}

$Y H Y, J L Q, X M W$ and GHL the conception and design of the study. HYL, HWH, DLH and YSW performed experiments. HYL, HWH, YSW, WXS, FL, ZLW and MKY acquisition of data, analysis and interpretation of data. HYL, DLH and WXS 
wrote the main manuscript text, prepared figures and statistical analysis. YHY final approval of the version to be submitted. All authors read and approved the final manuscript.

\section{Funding}

This research was supported by the National Natural Science Foundation of China (NSFC) $(21702100,31670298,31771413,21907051)$, the Program for Changjiang Scholars and Innovative Research Team in University (IRT_14R27), and the Fundamental Research Funds for the Central Universities (020814380002, 020814380057).

\section{Availability of data and materials}

The datasets used in this study are available from the corresponding author upon reasonable request.

\section{Ethics approval and consent to participate}

Experiments were approved by the Laboratory Animal Ethics Committee of School of Life Sciences, Nanjing University. Consent to participate is not relevant to this manuscript.

\section{Consent for publication}

Not applicable.

\section{Competing interests}

The authors declare that they have no competing interests.

\section{Author details}

1 State Key Laboratory of Pharmaceutical Biotechnology, Institute of Plant Molecular Biology, School of Life Sciences, Nanjing University, Nanjing 210023, People's Republic of China. ${ }^{2}$ Co-Innovation Center for Sustainable Forestry in Southern China, Nanjing Forestry University, Nanjing 210037, People's Republic of China. ${ }^{3}$ School of Life Sciences, Huaiyin Normal University, Huaian 223300, China.

Received: 1 February 2020 Accepted: 28 February 2020

Published online: 10 March 2020

\section{References}

1. Bray F, Ferlay J, Soerjomataram I, Siegel RL, Torre LA, Jemal A. Global cancer statistics 2018: globocan estimates of incidence and mortality worldwide for 36 cancers in 185 countries. CA Cancer J Clin. 2018;68(6):394424. https://doi.org/10.3322/caac.21492.

2. McGuire KP, Santillan AA, Kaur P, Meade T, Parbhoo J, Mathias M, et al. Are mastectomies on the rise? a 13-year trend analysis of the selection of mastectomy versus breast conservation therapy in 5865 patients. Ann Surg Oncol. 2009;16(10):2682-90. https://doi.org/10.1245/s1043 4-009-0635-x

3. Salminen E, Izewska J, Andreo P. laea's role in the global management of cancer-focus on upgrading radiotherapy services. Acta Oncol. 2005;44(8):816-24. https://doi.org/10.1080/02841860500341355.

4. Jordan VC, Robinson SP. Species-specific pharmacology of antiestrogens: role of metabolism. Fed Proc. 1987;46(5):1870-4.

5. Valabrega G, Montemurro F, Aglietta M. Trastuzumab: mechanism of action, resistance and future perspectives in her2-overexpressing breast cancer. Ann Oncol. 2007;18(6):977-84. https://doi.org/10.1093/annonc/ mdl475.

6. Jinno H, Sakata M, Hayashida T, Takahashi M, Sato T, Seki H, et al. Primary systemic chemotherapy of breast cancer: indication and predictive factors. Breast Cancer. 2011;18(2):74-9. https://doi.org/10.1007/s1228 2-010-0226-5.

7. Clemons M, Danson S, Howell A. Tamoxifen ('nolvadex'): a review: antitumour treatment. Cancer Treat Rev. 2002;28(4):165-80.

8. Early Breast Cancer Trialists' Collaborative G, Davies C, Godwin J, Gray R, Clarke M, Cutter D, et al. Relevance of breast cancer hormone receptors and other factors to the efficacy of adjuvant tamoxifen: patient-level meta-analysis of randomised trials. Lancet. 2011;378(9793):771-84.

9. Ring A, Dowsett M. Mechanisms of tamoxifen resistance. Endocr Relat Cancer. 2004;11(4):643-58. https://doi.org/10.1677/erc.1.00776.
10. deGraffenried LA, Friedrichs WE, Russell DH, Donzis EJ, Middleton AK, Silva JM, et al. Inhibition of mtor activity restores tamoxifen response in breast cancer cells with aberrant akt activity. Clin Cancer Res. 2004;10(23):8059-67. https://doi.org/10.1158/1078-0432.CCR-04-0035.

11. Clark AS, West K, Streicher S, Dennis PA. Constitutive and inducible akt activity promotes resistance to chemotherapy, trastuzumab, or tamoxifen in breast cancer cells. Mol Cancer Ther. 2002;1 (9):707-17.

12. Bachelot T, Bourgier C, Cropet C, Ray-Coquard I, Ferrero JM, Freyer G, et al. Randomized phase ii trial of everolimus in combination with tamoxifen in patients with hormone receptor-positive, human epidermal growth factor receptor 2-negative metastatic breast cancer with prior exposure to aromatase inhibitors: a gineco study. J Clin Oncol. 2012;30(22):2718-24. https://doi.org/10.1200/JCO.2011.39.0708.

13. deGraffenried LA, Chandrasekar B, Friedrichs WE, Donzis E, Silva J, Hidalgo M, et al. Nf-kappa b inhibition markedly enhances sensitivity of resistant breast cancer tumor cells to tamoxifen. Ann Oncol. 2004;15(6):885-90. https://doi.org/10.1093/annonc/mdh232.

14. Isabel C, Kimberly B, Susie C, Joyce S. The dual erbb1/erbb2 inhibitor, lapatinib (gw572016), cooperates with tamoxifen to inhibit both cell proliferation- and estrogen-dependent gene expression in antiestrogen-resistant breast cancer. Cancer Res. 2005;65(1):18-25.

15. Sharma D, Saxena NK, Davidson NE, Vertino PM. Restoration of tamoxifen sensitivity in estrogen receptor-negative breast cancer cells: tamoxifen-bound reactivated er recruits distinctive corepressor complexes. Cancer Res. 2006;66(12):6370-8. https://doi.org/10.1158/00085472.CAN-06-0402.

16. Weng SC, Kashida Y, Kulp SK, Wang D, Brueggemeier RW, Shapiro $C L$, et al. Sensitizing estrogen receptor-negative breast cancer cells to tamoxifen with osu-03012, a novel celecoxib-derived phosphoinositide-dependent protein kinase-1/akt signaling inhibitor. Mol Cancer Ther. 2008;7(4):800-8. https://doi.org/10.1158/1535-7163. MCT-07-0434.

17. Shen F, Xue X, Weber G. Tamoxifen and genistein synergistically downregulate signal transduction and proliferation in estrogen receptornegative human breast carcinoma mda-mb-435 cells. Anticancer Res. 1999;19(3A):1657-62.

18. Lin KH, Huang MY, Cheng WC, Wang SC, Fang SH, Tu HP, et al. Rna-seq transcriptome analysis of breast cancer cell lines under shikonin treatment. Sci Rep. 2018;8(1):2672. https://doi.org/10.1038/s41598-01821065-X.

19. Yao Y, Zhou Q. A novel antiestrogen agent shikonin inhibits estrogendependent gene transcription in human breast cancer cells. Breast Cancer Res Treat. 2010;121(1):233-40. https://doi.org/10.1007/s1054 9-009-0547-2.

20. Shahsavari Z, Karami-Tehrani F, Salami S, Ghasemzadeh M. Rip1k and rip3k provoked by shikonin induce cell cycle arrest in the triple negative breast cancer cell line, mda-mb-468: necroptosis as a desperate programmed suicide pathway. Tumour Biol. 2016;37(4):4479-91. https ://doi.org/10.1007/s13277-015-4258-5.

21. Chen JY, Liu ZC, Zeng Z, Huang WD, Yang YF, Zhu BH. Shikonin promotes autophagy of mcf-7 human breast cancer cells through pi3k/akt pathway. Chin Pharmacol Bull. 2013;29(2):194-8.

22. Jang $S Y$, Lee JK, Jang EH, Jeong SY, Kim JH. Shikonin blocks migration and invasion of human breast cancer cells through inhibition of matrix metalloproteinase-9 activation. Oncol Rep. 2014;31(6):2827-33. https:// doi.org/10.3892/or.2014.3159.

23. Zhang FL, Wang P, Liu YH, Liu LB, Liu XB, Li Z, et al. Topoisomerase i inhibitors, shikonin and topotecan, inhibit growth and induce apoptosis of glioma cells and glioma stem cells. PLOS ONE. 2013;8(11):e81815. https://doi.org/10.1371/journal.pone.0081815.

24. Chen J, Xie J, Jiang Z, Wang B, Wang Y, Hu X. Shikonin and its analogs inhibit cancer cell glycolysis by targeting tumor pyruvate kinasem2. Oncogene. 2011;30(42):4297-306. https://doi.org/10.1038/ onc.2011.137.

25. Hu X, Han W, Li L. Targeting the weak point of cancer by induction of necroptosis. Autophagy. 2007;3(5):490-2. https://doi.org/10.4161/ auto.4592.

26. Guo ZL, Li JZ, Ma YY, Qian D, Zhong JY, Jin MM, et al. Shikonin sensitizes a549 cells to trail-induced apoptosis through the jnk, stat3 and akt pathways. BMC Cell Biol. 2018;19(1):29. https://doi.org/10.1186/s1286 0-018-0179-7. 
27. Zhou G, Yang Z, Wang X, Tao R, Zhou Y. Trail enhances shikonin induced apoptosis through ros/jnk signaling in cholangiocarcinoma cells. Cell Physiol Biochem. 2017;42(3):1073-86. https://doi.org/10.1159/000478758.

28. He G, He G, Zhou R, Pi Z, Zhu T, Jiang L, et al. Enhancement of cisplatininduced colon cancer cells apoptosis by shikonin, a natural inducer of ros in vitro and in vivo. Biochem Biophys Res Commun. 2016;469(4):1075-82. https://doi.org/10.1016/j.bbrc.2015.12.100.

29. Wang Z, Yin J, Li M, Shen J, Xiao Z, Zhao Y, et al. Combination of shikonin with paclitaxel overcomes multidrug resistance in human ovarian carcinoma cells in a p-gp-independent manner through enhanced ros generation. Chin Med. 2019;14:7. https://doi.org/10.1186/s13020-019-0231-3.

30. Li W, Liu J, Jackson K, Shi R, Zhao Y. Sensitizing the therapeutic efficacy of taxol with shikonin in human breast cancer cells. PLOS ONE. 2014;9(4):e94079. https://doi.org/10.1371/journal.pone.0094079.

31. Luo H, Vong CT, Chen H, Gao Y, Lyu P, Qiu L, et al. Naturally occurring anticancer compounds: shining from chinese herbal medicine. Chin Med. 2019;14:48. https://doi.org/10.1186/s13020-019-0270-9.

32. Zhang $\mathrm{CH}$, Wang J, Zhang LX, Lu YH, Ji TH, Xu L, et al. Shikonin reduces tamoxifen resistance through long non-coding rna uc 57. Oncotarget. 2017:8(51):88658-69.

33. Zhu XJ, Shi Y, Peng J, Guo CS, Shan NN, Qin P, et al. The effects of baff and baff-r-fc fusion protein in immune thrombocytopenia. Blood. 2009;114(26):5362-7. https://doi.org/10.1182/blood-2009-05-217513.

34. Liang W, Cai A, Chen G, Xi H, Wu X, Cui J, et al. Shikonin induces mitochondria-mediated apoptosis and enhances chemotherapeutic sensitivity of gastric cancer through reactive oxygen species. Sci Rep. 2016;6:38267. https://doi.org/10.1038/srep38267.

35. Zhu Y, Yu Z, Yu Z, Liu Y, Zheng X. Acetylshikonin inhibits colorectal cancer growth via pi3k/akt/mtor signaling pathway. Chin Med. 2018;09(3):126-43.
36. Zhou Z, Lu B, Wang C, Wang Z, Luo T, Piao M, et al. Rip1 and rip3 contribute to shikonin-induced DNA double-strand breaks in glioma cells via increase of intracellular reactive oxygen species. Cancer Lett. 2017;390:77-90. https://doi.org/10.1016/j.canlet.2017.01.004.

37. Altenberg B, Greulich KO. Genes of glycolysis are ubiquitously overexpressed in 24 cancer classes. Genomics. 2004;84(6):1014-20. https://doi. org/10.1016/j.ygeno.2004.08.010.

38. Hayes EL, Lewis-Wambi JS. Mechanisms of endocrine resistance in breast cancer: an overview of the proposed roles of noncoding RNA. Breast Cancer Res. 2015;17:40. https://doi.org/10.1186/s13058-015-0542-y.

39. Chong CM, Su H, Lu JJ, Wang Y. The effects of bioactive components from the rhizome of salvia miltiorrhiza (danshen) on the characteristics of alzheimer's disease. Chin Med. 2019;14:19. https://doi.org/10.1186/s1302 0-019-0242-0.

40. Iyaswamy A, Krishnamoorthi SK, Song JX, Yang CB, Kaliyamoorthy V, Zhang $\mathrm{H}$, et al. Neurodefend, a novel chinese medicine, attenuates amyloid-beta and tau pathology in experimental alzheimer's disease models. J Food Drug Anal. 2020;28(1):132-46. https://doi.org/10.1016/j. jfda.2019.09.004.

41. Chai S, To KK, Lin G. Circumvention of multi-drug resistance of cancer cells by chinese herbal medicines. Chin Med. 2010;5:26. https://doi. org/10.1186/1749-8546-5-26.

\section{Publisher's Note}

Springer Nature remains neutral with regard to jurisdictional claims in published maps and institutional affiliations.
Ready to submit your research? Choose BMC and benefit from:

- fast, convenient online submission

- thorough peer review by experienced researchers in your field

- rapid publication on acceptance

- support for research data, including large and complex data types

- gold Open Access which fosters wider collaboration and increased citations

- maximum visibility for your research: over $100 \mathrm{M}$ website views per year

At BMC, research is always in progress.

Learn more biomedcentral.com/submissions 